\title{
"Nuestro norte son los niños" Subjetividades políticas y colectivización del cuidado infantil en organizaciones sociales del Gran Buenos Aires
}

\section{Laura Santillán ${ }^{1}$}

\author{
1 Instituto de Ciencias Antropológicas, Facultad de Filosofía y Letras, UBA/CONICET, Ciudad de Buenos \\ Aires, Argentina \\ Correo Electrónico: laursantillan@gmail.com
}

Recibido:

21 de mayo de 2019 Aceptado:

15 de octubre de 2019

doi: 10.34096/runa.v40i2.6282

\section{Resumen}

En este artículo nos proponemos analizar las nociones de infancia que distintos actores sociopolíticos ponen en juego en barrios populares del área metropolitana bonaerense. Nos referimos a iniciativas impulsadas por pobladores, voluntarios y militantes políticos que se han planteado una propuesta colectivizada del cuidado de los niños y las niñas. El análisis busca documentar los modos en que la elaboración de qué significan los niños y cuáles son sus necesidades tienen lugar conforme se moldean y gestan las subjetividades políticas de quienes impulsan las obras. Este proceso, lejos de quedar restringido a los adultos, involucra de lleno a los niños, quienes participan activamente de la construcción de las acciones que los tienen por objeto y del reconocimiento de sus necesidades. Nos basaremos en el registro proveniente del trabajo de campo antropológico y etnográfico que llevamos adelante desde el año 2001 en la zona norte y noroeste del Gran Buenos Aires.

\section{"Our north is children": political subjectivities and collectivi- zation of child care in social organizations of the Metropoli- $\tan$ Area of Buenos Aires}

\begin{abstract}
In this article we set out to analyze the images of childhood that different sociopolitical actors put into play in popular neighborhoods of the Metropolitan Area of Buenos Aires. We refer to initiatives promoted by residents, volunteers and political activists who have come up with a collectivized proposal for the care of children. We will base our analysis on the records that come from the anthropological and ethnographic field work that we have carried out since
\end{abstract}

\section{Palavras-chave}

Infancia; Subjetividades políticas; Colectivización del cuidado; Organizaciones sociales; Desigualdad

\section{Palabras clave}

Childhood; Political subjectivities; Collectivization of child care; Social organizations; Inequality 
2001 in the north and north-west of Buenos Aires city suburbs (Gran Buenos Aires). The analysis seeks to document the ways in which the production of images regarding children and their needs takes place as the political subjectivities of those who promote these actions are generated and shaped. This process, far from being restricted to adults, involves children fully, who turn out to be active in the processes of construction of those actions that have them as their object.

\section{"Nosso norte é criança": subjetividades politicas e coletivi- zação do cuidado infantil em Organizaçõ̃es sociais da Grande Buenos Aires}

\section{Resumo}

Palavras-chave

Criança; Subjetividades políticas; Coletivização do cuidado infantil; Organizacões sociais; Desigualdade
1. Los menores tutelados judicialmente, excluidos del sistema de escolarización centralizado, quedaron comprendidos dentro de intervenciones asociadas a lo que conoció como "modelo irregular" o "asistencialista".
Neste artigo propomos analisar as imagens da infância que diferentes atores sociopolíticos colocam em jogo nos bairros populares da Região Metropolitana de Buenos Aires. Referimo-nos a iniciativas promovidas por moradores, voluntários e ativistas políticos que elaboraram uma proposta coletivizada para o atendimento de crianças. Nos basearemos no registro que vem do trabalho de campo antropológico e etnográfico que realizamos desde 2001 no norte e no noroeste da Grande Buenos Aires. A análise busca documentar as formas pelas quais a produção de imagens sobre crianças e suas necessidades acontece à medida que as subjetividades políticas daqueles que promovem os trabalhos são moldadas e gestadas. Esse processo, longe de se restringir aos adultos, envolve plenamente os filhos, que se mostram ativos nos processos de construção das ações que se destinam a eles.

\section{Introducción}

Qué necesitan los niños y quiénes forman parte de su cuidado son interrogantes para los cuales no encontraremos respuestas universales. En las sociedades occidentales, la consolidación, en la modernidad, de la infancia como una etapa particular de la vida ha implicado la "fabricación" -con importante tendencia homogenizadora- de una serie de características y necesidades diferenciales respecto de otras edades. En la realidad de la Argentina, como expone el análisis historiográfico, las últimas décadas del siglo XIX y las primeras del XX, al clamor del proceso de construcción de un Estado nacional centralizado, fueron cruciales en la elaboración de clasificaciones y estratificaciones sobre la población infantil en tanto promovieron la segmentación entre aquellos escolarizados y los menores tutelados judicialmente (Carli, 2002). ${ }^{1}$ Diversos estudios han dado cuenta de las condiciones en que esta segmentación se ha actualizado en diferentes momentos de nuestro país, conforme con las modalidades asumidas por las políticas públicas y las intervenciones sociales (Llobet, 2010; Gentile, 2011; Villalta, 2012). En cuanto a nuestra disciplina, es importante decir que, tempranamente, contribuyó a comprender cómo la concepción acerca de lo que es la niñez y qué se considera adecuado para este grupo, qué características o comportamientos son esperables, no es un dato dado por la naturaleza, sino el resultado de disputas de sentido, en las que algunos postulados intentan imponerse como visión legítima y universal (Fonseca 1998; 
Colángelo, 2005; Szulc, 2006; Villalta, 2010; Cerletti, 2014; Barna, 2015; Santillán y Novaro, 2017).

Para desarrollar este artículo nos apoyamos en el conocimiento ya consolidado sobre los procesos de construcción de la infancia, procurando en nuestro caso definir aquello que necesitan los niños y las niñas y cómo debieran ser cuidados desde el estudio experiencias concretadas en organizaciones sociales de barrios populares del Gran Buenos Aires. Específicamente hacemos referencia a iniciativas impulsadas por actores de base (pobladores, voluntarios y militantes sociales y políticos), que se han planteado una propuesta colectivizada del cuidado de los niños ${ }^{2}$ en su propio lugar de residencia o próximos a ella. Citando a Nancy Fraser, este análisis resulta sugestivo, ya que nos aproxima a los modos en que, generadas desde posiciones subordinadas, las necesidades pueden ser leídas, incluso, desde sus sentidos contestatarios y politizados (Fraser, 1991).

Si bien en trabajos previos hemos avanzado en la documentación de la naturaleza política de las definiciones que distintos actores producen respecto de los niños (Santillán, 2012, 2015), en esta oportunidad el objetivo es ahondar en el modo en que las imágenes de infancia y las formas que asume el cuidado ${ }^{3}$ se establecen a conforme se moldean y gestan las subjetividades políticas de quienes impulsan las obras. Esto implica, siempre en relación con este objetivo, describir de manera más pormenorizada las circunstancias en las que los pobladores, voluntarios y militantes toman posición respecto de los niños, elaboran propuestas sobre el cuidado y las necesidades infantiles, y siendo partícipes activos en las organizaciones que fundaron, se invisten progresivamente en procesos de producción política. Paralelamente, aludimos a un avance en la producción colectiva, que en el marco de afectividades y saberes en constante construcción no se ciñe al mundo adulto, sino que involucra de lleno a los propios niños. Tal como veremos, los niños y adolescentes, destinatarios de las acciones de cuidado, han sido activos en los procesos de construcción comunitaria, ya sea incidiendo en las propuestas a partir de su demanda o creando dinámicas propias a las acciones y procesos que los tienen por objeto de intervención.

El siguiente análisis está fundamentado en los registros producidos en el trabajo de campo antropológico (Achilli, 2005; Rockwell, 2009) iniciado en el año 2001, realizado en organizaciones sociales ubicadas en asentamientos y barrios populares del norte y noroeste del Gran Buenos Aires (en los partidos de Tigre y San Fernando respectivamente; al presente, en José C. Paz). Mientras entre 2001 y 2007 nos focalizamos en asociaciones de base cuyo trabajo estaba concentrado en la escolaridad, desde 2008 hasta la actualidad avanzamos en el reconocimiento de espacios comunitarios que, levantados esencialmente por pobladores de los asentamientos, ofrecen variadas actividades a los niños (copa de leche, ayuda escolar, recreación, deportes y acciones destinadas al cuidado de la primera infancia). ${ }^{4}$ A este registro sumamos el material elaborado desde el año 2015 a partir de proyectos de extensión universitaria cuyo objetivo está asociado a las investigaciones mencionadas. ${ }^{5}$ Respecto de las estrategias metodológicas, hemos realizado observación participante en distintas instancias de la vida cotidiana de los centros y organizaciones sociales, fundamentalmente actividades organizadas por los adultos: interacciones entre los niños en momentos de trabajo, esparcimiento, de entrada y salida de las instituciones y la comensalidad. De manera articulada con estas observaciones, realizamos entrevistas efectuadas desde la perspectiva antropológica a voluntarios sociales, militantes y referentes barriales, y a niños y adolescentes
2. En lo que sigue, cuando aludamos a "niños", daremos cuenta de los niños y las niñas.

3. Partimos de una definición de cuidado en tanto manifestación sociocultural, la cual constituye un conjunto amplio -y a la vez específico- de actividades y bienes que se estructuran en función del sostenimiento, la reproducción y producción de los sujetos. Como tal, por tanto, atañe a las prácticas materiales y también intangibles (afectivas, morales, emocionales) que permiten a las personas el desenvolvimiento de la vida (Santillán, 2014).

4. Esta etapa de investigación refiere a los proyectos individuales que venimos llevando adelante dentro de la Carrera de Investigadora en el CONICET, así también a los proyectos colectivos dentro de la Programación UBACyT y PICT-FONCyT radicados en el Instituto de Ciencias Antropológica (Facultad de Filosofía y Letras, Universidad de Buenos Aires) y que dirigimos junto a Laura Cerletti.

5. Nos referimos a los proyectos “Inclusión educativa de niños y jóvenes" (2015-2016) e "Infancia, educación y sociedad" (2017-2018) dentro del Programa de Voluntariado Universitario, Secretaría de Políticas Universitarias, Ministerio de Educación de la Nación. 
7. Se trató de la realización de talleres que llevamos adelante en ocasiones con la participación de los educadores, aplicando actividades participativas (rondas de intercambio y puesta en común con temáticas elegidas por los niños; talleres con la elaboración de láminas y dibujos sobre la vida en el barrio, la vida en los centros; trabajo de retrospectiva a partir de soporte fotográfico con jóvenes que habían asistido de niños a las organizaciones comunitarias).

8. Se contó con consentimiento informado de los niños y

niñas a partir de la notificación a padres y/o tutores a cargo y ellos mismos. Esta gestión contó con la colaboración de las organizaciones barriales gracias al contacto directo con los adultos referentes del trabajo de campo.

6. Del total de entrevistas, diez fueron realizadas a voluntarios sociales (tres hombres y siete mujeres, adultos de mediana edad, varios de ellos profesionales que ejercían su trabajo de voluntariado en forma paralela a su profesión); siete a militantes (jóvenes adultos de entre 30 y 42 años de edad, quienes habían sido estudiantes universitarios y/o egresados); doce referentes barriales (hombres y mujeres adultos, de mediana edad, pobladores de los barrios: dos de los hombres se dedicaban al cuentapropismo; las mujeres entrevistadas cumplían funciones, o bien como efectoras de programas sociales -Plan Más Vida-, o como receptoras de subsidios estatales

-Programa Argentina Trabaja y Asignación Universal por Hijo-). que integran los centros. ${ }^{6}$ En cuanto a los niños y adolescentes, nos hemos vinculado con ellos en sus actividades cotidianas, pero también en acciones específicamente planificadas bajo la forma de talleres y tareas participativas, ${ }^{7}$ además de entrevistas pautadas y llevadas adelante en los centros comunitarios y en los contextos familiares. ${ }^{8}$

En términos de debate, siempre en función del objetivo que nos propusimos, la intención es contribuir a la discusión en torno al campo de posibilidades o constricción que se pone en juego en los procesos de producción de sentidos relativos a la infancia y el cuidado, sobre todo si hacemos referencia-como en este caso- a proyectos colectivos emergentes. Concretamente, la finalidad es confrontar con visiones que tienden a interpretar de manera monolítica a las iniciativas populares al caracterizarlas o bien desde sus sentidos exclusivamente emancipatorios o bien, como reproducción rasa de lo instituido. Aludimos a interpretaciones que, además, suelen recortar en la participación de algunos sujetos y no todos (los vinculados a la militancia orgánica y no aquellas participaciones más intersticiales) ajustados asimismo al mundo adulto y no a los niños y niñas.

Tomando como parámetro los aportes de Parth Chartejee (2011), el problema está dado en la inclinación a comprender a las propuestas populares emergentes como si se tratara de "proyectos acabados", en que los sujetos movilizan sus prácticas y construcciones de sentido de manera lineal y a partir de contenidos siempre contestatarios y/o sin variación alguna en el transcurso de las acciones. A contramarcha de esta tendencia, nos nutrimos de un conjunto de estudios que en los últimos años aportaron, desde perspectivas renovadas, contenidos significativos para saber cómo se configuran, en el marco de relaciones sociales y políticas determinadas -estructuradas en base al poder y la dominación-, las posibilidades de agencia de los sujetos (Roseberry, 2007; Grossberg, 2012; Massey, 2012). En esa línea, nos interesamos por las realizaciones y sentidos que producen en términos de subjetividades políticas las personas entrevistadas (Alvarado, Botero y Ospina, 2010). Desde esta categoría -en la perspectiva que seguimos- la subjetividad no es pasible de ser reconstruida en base a algún principio ontológico inmutable o intencionalidad suprahistórica (González, 2012), sino en tanto experiencia social que surge cuando los individuos se abocan colectivamente para generar condiciones que les permitan crear y disputar en el ámbito público las necesidades que surgen en la vida en común (Alvarado, et al, 2010, González, 2012). De este modo, lejos de pensar que los sujetos ya están, más allá de donde se encuentren, dotados de poder, partimos del interrogante acerca de cómo los sujetos logran posicionarse en un lugar de poder -siempre en términos contextualizados- $\mathrm{y}$, a partir de allí, actúan (Grossberg, 2012). En el análisis que sigue nos interesa situar el estudio de la política en la vida cotidiana (Grossberg, 2012), en la cual las trayectorias de las personas son abordadas conforme con las múltiples movilidades que realizan, atentas a los cursos de acción (De Certeau, 1996) y desplazamientos entre lugares y articulaciones siempre heterogéneas (Ingold, 2015). Nos servimos, por tanto, de los desarrollos teóricos centrados en los procesos de producción cultural y política de la vida social, con particular interés en aquellos que se interiorizan en la capacidad de apropiación activa de los sujetos (Rockwell, 2009) y en la construcción de hegemonía y contestación cotidiana (Roseberry, 2007).

Estos aportes permitirán dar cuenta de las formas en que el cuidado de los niños es producido en nuestras sociedades como objeto político, pero también 
como parte de los procesos de politización de la vida en espacios que incluyen y rebasan los carriles más formalizados.

\section{Imágenes de infancia y subjetividades políticas en cursos de acción colectiva}

Tempranamente, en Argentina se crearon dispositivos de atención y cuidado de la infancia. A fines del siglo XIX, en el marco de la política pública, la Ley de Educación común 1420 promovió al sistema escolar como espacio legitimado para la formación de los futuros ciudadanos (Carli, 2002). Pero ya en la Buenos Aires colonial, una serie de agencias configuraron un campo de intervención hacia la niñez que veló por su cuidado a partir de la imposición de un conjunto de regulaciones -algunas de ellas, sobre la crianza familiar-y también la creación de instituciones de amparo (Moreno, 2000).

Y de modo progresivo, en la Argentina del siglo XX, las representaciones acerca de la atención y el cuidado de las infancias se condensarían en dos instituciones centrales: familia y escuela. Sin embargo, en diversos barrios, principalmente ubicados en la periferia de los centros urbanos de nuestro país, ${ }^{9}$ es posible identificar experiencias colectivas destinadas a la infancia que rebasan las fronteras del mundo doméstico y la escuela común:

Somos libres nació en el noventa y ocho. Nació en mi cocina y en el patio de mi casa [...] Como siempre digo, yo no sabía en qué me estaba metiendo cuando... Fue la necesidad. Porque en esa época, Argentina estaba pasando por un momento difícil y empezaron los planes. Las mujeres empezaron a salir a trabajar y no había quién cuidara a los chicos. Y, entonces, claro, yo era mamá y me preocupaba lo que pasaba. Este barrio no es ni la sombra de lo que era, porque era mucho campo, muchas casas separadas, y entonces algunas de las mujeres que salieron a limpiar veredas, yentonces los nenes se quedaron solos. (Entrevista a Rosa, pobladora y coordinadora en un Centro comunitario, Partido de José C. Paz, 18 de abril de 2018) ${ }^{10}$

Tal como expone Rosa en su testimonio, en esta fracción del Gran Buenos Aires, al igual que en otras zonas del área metropolitana, grupos de pobladores, voluntarios sociales, a la par de militantes de movimientos sociales y políticos, paulatinamente fueron haciendo suya -por fuera de los carriles formalizados del Estado y/o del mercado- la tarea de organizar acciones destinadas a los niños. Merenderos, apoyo escolar, centros culturales, centros infantiles han sido algunas denominaciones forjadas a lo largo del tiempo por quienes sostienen dichas iniciativas. Regularmente, los chicos y las chicas se acercan hasta las instalaciones levantadas por los propios pobladores -mayoritariamente mujeres- y militantes para realizar distintas acciones que se organizan para ellos. Porque en estos espacios es usual que los chicos no solo reciban refuerzo alimentario, sino actividades escolares y educativas, así como también recreativas y concernientes al cuidado.

En la provincia de Buenos Aires, jurisdicción en la que se inscribe nuestra indagación, la cobertura estatal en educación escolarizada -garantizar la jornada completa- y en relación con los niños y niñas de menor edad -creación de jardines de infantes y maternales- se destaca por su insuficiencia. Esta es una cuestión prioritaria y en torno a la cual ahonda vasta bibliografía. Aun así, entendemos, no termina de ser explicativo -al menos de manera cabal- para comprender qué circunstancias y procesos entran en juego cuando grupos de pobladores y/o militantes se disponen a impulsar, ya sea dentro o fuera
9. Junto con la ciudad y provincia de Buenos Aires, nos referimos a centros urbanos ubicados en las provincias de Córdoba, Santa Fe, Mendoza y Río Negro, entre otros.

10. Entrevista realizada junto a Antonella Rodríguez Franchi en el marco del proyecto de extensión universitaria "Infancia, educación y sociedad” (Programa Compromiso Social Universitario, Secretaria de Políticas Universitarias, Ministerio de educación de la Nación). 
Nos referimos a las movilizaciones y estallidos populares acontecidos los días 19 y 20 de diciembre del año 2001, que derivaron en la destitución del entonces presidente Fernando de la Rúa.

12. Como señalamos en trabajos previos, la participación de voluntarios y voluntarias de la Iglesia católica comprende un amplio abanico que va desde aquellos seguidores de la teología de la liberación y la opción por los pobres, hasta los vinculados al área de Cáritas, rama asistencial de la Iglesia católica. de organizaciones sociales preexistentes, proyectos colectivos con eje en la infancia.

En nuestra zona de estudio, la creación de organizaciones comunitarias destinadas a los niños se enmarca en momentos claramente identificables de conflictividad social en Argentina. Como expusimos en trabajos previos, coyunturas tales como ha sido la compleja situación hiperinflacionaria en el año 1989 o la crisis del año $2001^{11}$ son paradigmáticas para explicar la creación de buena parte de las iniciativas que estamos describiendo (Santillán, 2012, 2014). Distinta bibliografía se encargó de señalar el importante papel paliativo y compensador que tuvieron y tienen las asociaciones de base (Rosemberg, 1999; Cardarelli, 2005). Este es, por cierto, un punto relevante a tener en cuenta. Sin embargo, según consideramos, circunscribir el surgimiento de las organizaciones territoriales destinadas a la infancia a respuestas meramente "defensivas" frente a circunstancias conflictivas es dejar afuera del análisis una multiplicidad de factores, como por ejemplo, conocer quiénes son los sujetos que protagonizaron estas acciones y desde qué lenguajes, expectativas o visiones sobre los niños y sus necesidades.

En cuanto a los protagonistas, nuestra indagación en el norte y noroeste del Gran Buenos Aires nos puso frente a experiencias llevadas adelante por actores sociopolíticos distintivos: por un lado, mientras en algunas zonas las iniciativas fueron encaradas principalmente por voluntarios sociales, muchas de ellas mujeres vinculadas a la Iglesia católica -aunque no solamente- ${ }^{12}{ }^{2}$ en varios barrios la gestión de espacios para la niñez fue encaminada por militantes de movimientos sociales y estudiantes universitarios. Otra intervención es la gestada por los propios pobladores, quienes organizaron espacios para los chicos de manera asociada a las anteriores participaciones, pero de forma autogestiva. En trabajos previos aludimos a la diferencia en cuanto a las expectativas y acciones llevadas adelante por estos colectivos, en buena medida, conforme con los modos en que fueron definiendo y posicionándose en torno a lo político y la participación política (Santillán, 2015). Sin desatender estas distinciones que, cuando corresponda, puntualizaremos, en virtud de cómo se producen las nociones de infancia es factible identificar importantes continuidades.

Al decir de los protagonistas, el cuidado, en los ámbitos donde los niños desenvuelven su vida, no es una cuestión "dada", ni mucho menos algo garantizado, y por ese motivo resulta fundamental generar un lugar específico para ellos. La desigualdad social es interpretada como proceso que oprime, sin mayores miramientos, posibilidades concretas de desarrollo de su vida. Esto particularmente es así para el caso de los grupos de vecinos que, con el correr del tiempo, decidieron levantar un espacio para los niños en las inmediaciones de sus hogares, cuando no en el propio domicilio. La falta de acceso a derechos básicos formó y forma parte de la vida de quienes promovieron y promueven las obras. No obstante, como exponen algunos autores, las estructuras no solo oprimen y constriñen, sino que también dan poder y habilitan, esto es, posibilitan la acción (Grossberg, 1992).

Pese a su procedencia heterogénea, quienes conducen instituciones barriales comparten la inquietud por tratar de forjar un concepto distinto sobre niños, niñas y adolescentes -muchas veces, sus propios vecinos- para confrontar con estigmatizaciones arraigadas en las instituciones estatales. Y entre nuestros entrevistados, un común denominador ha sido encuadrar, desde el principio, a los niños como sujetos de privilegio y necesitados de protección: 


\begin{abstract}
Nuestro norte son los niños. Acá hacemos todo para que se sientan bien. Decoramos los salones para que estén en un lugar agradable, nos fijamos mucho en el menú, en la comida, claro. Nunca le vamos a fallar, el [centro] de apoyo siempre va a estar, todos los días del año, para todos ellos, para cada cual, cada uno con sus necesidades. Nuestro norte son los chicos. Por ellos estamos acá. (Entrevista a Marta, coordinadora en un centro de apoyo escolar, Distrito de Tigre, 20 de junio de 2005)
\end{abstract}

Coincidimos con otros estudios al afirmar que, en contextos atravesados por violencia y conflictividad, los adultos a cargo de iniciativas, como es el caso de Marta, lejos de sostener definiciones esencialistas de las infancias -y de las edades de la vida-, construyen una visión situada sobre los niños y adolescentes (Padawer, 2003). La separación de las edades de la vida, como bien se ha desarrollado dentro de la teoría social, se sustenta en clasificaciones que, en tanto categorías relacionales, cobran sentidos específicos conforme con el contexto en que se construyen y dinamizan (Bourdieu, 2000).

Cuando nuestros entrevistados describen su trabajo con la infancia, un aspecto que no pasa desapercibido es la incesante innovación en las iniciativas. Las acciones se van volviendo inteligibles durante largos procesos y se caracterizan por su persistente transformación. En consonancia con ello, lejos de permanecer estática y fija, la mirada sobre los niños y lo que ellos necesitan muta. Y muta en simultáneo se transforma la propia trayectoria biográfica. En los escenarios donde investigamos, este desarrollo para nada lineal sobresale por sus avances pero también por sus incertidumbres, por tratarse de construcciones abiertas y sustentadas en un continuo aprendizaje. Al relatar sus experiencias, militantes, voluntarios sociales y pobladores suelen destacar el proceso formativo y transformador que surge del trabajo con los niños.

¿En qué consistió dicho proceso? Marcos, Estela, Gladys, vecinas y vecinos que, en distintos barrios, abrieron de manera articulada con otros pobladores un espacio de ayuda escolar y refuerzo alimentario cercano a sus domicilios fueron exhaustivos al describir el desenvolvimiento del trabajo realizado. Y, al relatar sus experiencias sobre el curso de las obras, expresan un natural reconocimiento por el trabajo de construcción compartida, que comprende varias dimensiones. En primer lugar, se trata de un "hacer junto con otros", que no acontece de manera inmediata, sino enmarcado en acciones de organización social y colectiva, muchas preexistentes, principalmente para resolver vicisitudes de la vida compartida. Como expone la bibliografía relativa al tema, el reconocimiento de un ámbito específico para la subjetividad política va unido al reconocimiento de una construcción de sentido que tiene por objeto "lo público" y la creación de una vida común (González, 2012). Al respecto, como desarrollamos en trabajos previos, y así lo hicieron también otros trabajos antropológicos representativos en el tema, en la experiencia de buena parte de los asentamientos que conocimos, la organización urbana y/o de la ocupación de la tierra abrió una serie de acciones que fueron sedimentando prácticas compartidas, aprendizajes y afianzamiento de relaciones muy significativas (Manzano, 2013; Woods, 2007; Santillán, 2012). En segundo lugar, aludimos a interacciones sustentadas en el conocimiento mutuo y, fundamentalmente, en el afecto, que nace entre vecinos y a raíz de vínculos de sociabilidad originados entre militantes y pobladores ${ }^{13}$. En el devenir de las iniciativas, la afectividad -y esto es así en las distintas intervenciones- ocupa un lugar muy importante. Como han señalado distintos estudios, entendemos que el poder del afecto en las experiencias que estamos describiendo no reside tanto en su contenido, sino en el hecho de que constituye un importante vector de inversión a partir del cual las articulaciones resultan posibles (Grossberg, 1992). Dicho en otros
13. Para un análisis en profundidad sobre la relación entre militantes políticos y pobladores de los barrios en donde se desarrollan acciones colectivas se puede consultar a Cura (2013). 
14. En la zona norte y noroeste del Gran Buenos Aires, son cuatro las redes que nuclean a los centros y organizaciones sociales destinadas a la infancia. Mientras en la zona norte se trata de la Red de Apoyo Escolar y Educación Complementaria (RAE), que inició sus acciones en 1989, y la RADI, que nuclea principalmente a los centros de apoyo escolar de la diócesis de San Isidro; en la zona noroeste se encuentra la red El Encuentro (que comprende organizaciones en los partidos de José C. Paz, Moreno, Malvinas Argentinas, San Miguel y San Fernando), y Andando (Moreno y Merlo). Cabe decir que dichas redes integran además el colectivo Inter-Redes, al cual se integra, entre otros, la Coordinadora de Jardines Maternales de La Matanza.

15. Por el Movimiento Campesino de Santiago del Estero, que agrupa familias campesinas de la provincia y basa su accionar en la lucha por la tierra y el desarrollo de emprendimientos productivos autogestivos.

16. En referencia al equipo de educación popular que surgió en el marco de la Universidad de Madres de Plaza de Mayo hacia el año 2001.

17. Entrevista realizada junto a Antonio Doval en el marco del proyecto de extensión universitaria "Infancia, educación y sociedad" (Programa Compromiso Social Universitario. Secretaria de Políticas Universitarias. Ministerio de educación de la Nación, 2016-2018). términos, los sentimientos, y no solo las cogniciones, se tornan catalizadores de la disputa y la decisión de producir posición frente a las realidades que se viven (Vargas, López y Guevara, 2009). En nuestra indagación, quienes son partícipes de los espacios que albergan a los chicos reconocen lo importante que ha sido transitar de manera conjunta una serie de circunstancias y acontecimientos, vehiculizados mayoritariamente en base a una economía afectiva, eficaz y activadora de compromisos mutuos y trayectorias asociativas.

Sumado a las dos cuestiones anteriores, el proceso formativo y transformador al que hicimos referencia está sustentado en una serie de movimientos que fueron realizando los propios sujetos. Aludimos a cursos de acción y movilidades que tuvieron lugar, como dijimos, estando con otros (Massey, 2012), y produjeron efectos hondos en la subjetividad. Según entendemos, el análisis de las imágenes de infancia es inescindible, entonces, de los sentidos que generan quienes encaminan las obras colectivas de cuidado desde nuevas posiciones y lugares que fueron ocupando. En el transcurso de las iniciativas, voluntarios, militantes y pobladores no solo comenzaron a nuclearse en el trabajo en red, sino que tejieron relaciones con centros de similares características y se integraron a diversificados circuitos formativos. Este punto es central, pues, surgidas a raíz de las propias iniciativas de los centros comunitarios, las redes de organizaciones sociales ${ }^{14}$ que trabajan con la infancia son referencias reiteradas y muy significativas entre educadores y voluntarios:

Y en esa época la red estaba muy conectada al MOCASE. ${ }^{15}$ Teníamos otras conexiones. También ahí estábamos con el movimiento Los chicos del Pueblo. Entonces necesitábamos darle más herramientas a nuestros pibes. Analizar un poco más por qué estábamos como estábamos. Y se pensó en estos talleres y en crear un lugar particular para que todos puedan estar ahí, y no un día uno, un día otro. (Entrevista a Jorge, educador en un centro comunitario, partido de José C. Paz, 16 de mayo de 2018).

Nosotros damos apoyo escolar y nos formamos afuera del centro. En el espacio que cada cual se sienta cómoda. Hay compañeras que le gusta el espacio género, la red da espacios de género de niñez. Hay compañeras que se forman en pedagogía popular. Está Pañuelos en rebeldía. ${ }^{16}$ Eso es muy importante, tenemos los talleres de Pañuelos en rebeldía (Entrevista a Claudia, pobladora y educadora en un centro comunitario, Partido de Tigre, o9 de marzo de 2015)

Las movilidades y desplazamientos a raíz de integrar diversos colectivos y de ocupar distintos lugares, para muchos protagonistas de las iniciativas tiene como uno de los efectos más significativos la ruptura con adscripciones previas. Así lo relata Carmen, una pobladora que intervino de manera activa en el emplazamiento de un centro en el partido de José C. Paz:

Yo pertenecía a la iglesia, yo milité muchos años en la iglesia. Después, hace unos años me fui porque, bueno, por no coincidir con muchas cosas. ¿Y quién éramos nosotros para decir que el chico tenía que agradecer a Dios, al padre, al Centro, a todo?, si era un derecho que le corresponde. El estar bien cuidado, el estar alimentado, está en su derecho. Entonces quién éramos. Pero eso lo fuimos descubriendo. (Entrevista a Carmen, pobladora y educadora en un centro comunitario, Partido de José C. Paz, o9 de mayo de 2018) ${ }^{17}$

Los lugares, como expone Tim Ingold (2015), son delineados por el movimiento, no por sus límites externos. Siguiendo este razonamiento, podemos indicar que las personas integrantes de las iniciativas que describimos -como 
ocurre en otras similares- frecuentan los espacios como "habitantes" y no como "locales". Lejos están así de quedar confinados dentro de un lugar particular o de que su experiencia quede circunscrita a horizontes restringidos (Ingold, 2015). Al decir de los protagonistas de las acciones, este "hacer" y "encontrar$\mathrm{se}^{\prime \prime}$ en la tarea de cuidar y atender a los niños y las niñas contó con efectos no necesariamente previstos, como una transformación en la forma de verse y de ver al mundo, que modificó los sentidos otorgados a la infancia y la propuesta para con ellos mismos. Acompañando el sentir de Carmen, así lo reflexionaba Jorge, educador en un centro, en la entrevista:

Entonces se da esto de romper con un montón de cuestiones que se venían haciendo. Se castigaba a los pibes. Estas son cosas, decían las compañeras [por aquellas más antiguas]: a nosotros nos castigaban en la escuela, por qué no vamos a castigar a los chicos ahora. Entonces no estaba mal visto, o sea, y era normal. [...] Entonces era como algo aceptado en un montón de cosas. Ahí empezar a pensar cómo, desde la profesionalización -es decir, una forma de decirlo-, se empieza a pensar que teníamos que sistematizar lo que hacíamos y empezar a darle como un sustento y un apoyo teórico, que es donde se empieza a pensar desde la metodología de Pablo Freire y demás. (Entrevista a Jorge, educador en un centro comunitario, Partido de José C. Paz, 16 de mayo de 2018)

Transcurrida la etapa inicial en la vida de las organizaciones, la percepción de los niños como sujetos de derechos, la atención a las relaciones de género, la implicancia de la participación política, comienzan a conformar la base ideológica y filosófica del trabajo con las chicas y los chicos. En el devenir de los acontecimientos, la recuperación por parte de la mayoría de las organizaciones sociales -sobre todo, de aquellas nucleadas en red-del programa de la educación popular se tornará crucial en las transformaciones, como así también en las retóricas que se vuelven muy significativas en el trabajo con la infancia, como es la sustentada en el paradigma de los derechos. Como exponen otros trabajos, el régimen de los derechos del niño, producto de la Convención Internacional de los Derechos del Niño de 1989, ha permeado de manera profusa a diversas instituciones y espacios que trabajan con la infancia (Grinberg, 2008; Barna, 2012).

En el flujo de estas transformaciones -y configuración de las subjetividades-, que entendemos, como expusimos, en términos de subjetividades políticas, las acciones que comienzan a sistematizarse en los centros, por el mismo hecho de ser planteadas, abren un campo de disputa acerca de cómo debe transitarse la experiencia de "ser niños" en barrios atravesados por la desigualdad y la conflictividad social:

Porque en la ludoteca trabajan mucho lo psicológico, el problema socioeconómico, problemas personales, entonces chupan al niño, lo chupan al niño, porque lo religioso hace eso, chupar al niño con tratar de solucionar sus problemas personales, pero no es que le dan una herramienta para solucionarlos ellos mismos, si no que yo te soluciono el problema, entonces, porque Dios me ayuda. [...] Está siempre lo caritativo, y la explicación: porque es Dios el que me ayuda, Dios me da esto, Dios me da lo otro, como que es iDios! (Entrevista a Micaela, pobladora y educadora de un centro comunitario, Distrito de Tigre, 26 de agosto de 2010).

Ahora bien, tal como veremos en el siguiente apartado, en simultáneo los responsables de las obras producen acciones con foco en la infancia, se configuran de manera activa las experiencias y subjetividades de los niños y las niñas quienes protagonizan iniciativas diversificadas y significativas. 


\section{Imágenes de infancia y sus necesidades desde el protagonis- mo de los niños en las iniciativas comunitarias}

El análisis de la producción de nociones de infancia y su cuidado por parte de pobladores, militantes y voluntarios sociales no implica dejar afuera el lugar activo que, desde el inicio de las obras, sostuvieron quienes son sus principales destinatarios: niños y adolescentes. Siempre basándonos en los cursos de acción que se han podido materializar -en los que fueron sustanciales la interacción y las relaciones que estrecharon entre sí y/o con los adultos-, los niños y las niñas con quienes nos contactamos a lo largo de la investigación demostraron ser portavoces clave en cuanto al sostenimiento y la recreación de propuestas dentro de los espacios barriales y dejaron al descubierto cuáles son sus necesidades. Atender a estas cuestiones nos sitúa dentro del sugestivo debate acerca de cómo en nuestras sociedades las jóvenes generaciones encaran acciones de participación y producción social, y de cómo estos procesos son recuperados desde la investigación, dentro y fuera de nuestra disciplina.

Según advierten diversos estudios, la discusión sobre la participación social de la infancia contiene como uno de sus desafíos el hecho de que, por su propia enunciación, los postulados acerca de los niños y jóvenes como sujetos con protagonismo político en el espacio público cuestionan de lleno discursos con fuerte vigencia que, a partir de categorías sociales y académicas, continúan exaltando la minoridad y necesidad de protección de la niñez (Batallán, 2011). Dentro del campo de estudios de la antropología, si bien los niños no estuvieron del todo ausentes en los orígenes de la disciplina (Szulc, 2006; Santillán, et al., 2008), hasta al menos las últimas décadas, dentro de las ciencias sociales, la niñez fue entendida como una etapa transitoria, carente de valor propio (Scheper Huges, 1998), como reproductora de la cultura adulta (Hardman, 1973), y/o espectadora pasiva del ambiente opresivo que afecta y produce sus comportamientos (Hardman, 1973; Szulc, 2006).

Progresivamente, una serie de investigaciones antropológicas han venido incorporando a los niños en sus indagaciones y ahondaron en el análisis de las apropiaciones que estos realizan en tanto productores de significados (Cohn, 2005; Szulc, 2006; Pires, 2007, García Palacios y Hecht, 2009; Enriz, 2010; Santillán, 2012; Shabel, 2016). Con respecto a los avances elaborados en torno a la incorporación de las voces de los niños, tal como señalan varios autores, es necesario atender a los límites que plantean algunos análisis relativos al énfasis que otorgan a la autonomía y agencia infantil (Szulc, 2006; Pires, 2007), lo que produce como riesgo aislar analíticamente a los niños y las niñas de las tramas de relaciones y prácticas sociales en las cuales se insertan (Szulc, 2006; Villalta, 2010; Santillán, 2012; Cerletti, 2014).

En paralelo a las propuestas que se formularon para propiciar la participación de los chicos -en relación con las cuales los responsables de los espacios encontraron logros y limitaciones-, en el transcurso de la investigación fuimos testigos de una serie de acciones que propiciaron, como desarrollaremos a continuación, los propios niños y adolescentes en el flujo de la cotidianeidad y que originaron cambios en las decisiones ya asumidas dentro de un centro comunitario.

Como dijimos, es una aspiración de las experiencias comunitarias revisar en forma continua la organización de los tiempos y espacios de trabajo y plantear incluso una propuesta lo suficientemente flexible para atender a las necesidades de los chicos. Una cualidad de los centros comunitarios llevados adelante 
por pobladores, voluntarios y militantes ha sido romper con la organización de los grupos de niños y niñas a partir de la separación por edades, tal cual es la estructura del sistema graduado, propio de la escuela común. Y en el caso de las acciones comunitarias vinculadas con la escolaridad, el criterio que suele primar se relaciona con el nivel de avance y/o desarrollo en los aprendizajes. Los responsables de las organizaciones barriales hacen significativos esfuerzos por interpretar lo que requieren los chicos, para intentar adecuar las respuestas a esas necesidades. Ahora bien, los niños y las niñas, tal como hemos podido documentar desde la investigación, ocupan activamente los espacios, y en ocasiones ponen en entredicho el trasfondo asociado a cómo los adultos han interpretado lo que ellos necesitan.

A saber, en el marco de la flexibilidad de tiempos y espacios, los niños logran diariamente -muchas veces en asociación con otros- modificar rutinas y decisiones que los adultos tomaron tras largos procesos de discusión. Al respecto, en la vida cotidiana de las organizaciones sociales es frecuente, por ejemplo, que los niños alteren, cuando no subviertan, ${ }^{18}$ el uso de salones y otros espacios comunes (a aquellos destinados para actividades escolares los convierten en sectores de juego o viceversa). En lo que respecta al empleo de las salas destinadas al trabajo, en los niños y las niñas, alianzas ligadas al compañerismo y la exigencia de dar continuidad a lazos que exceden a los centros -por ejemplo, los vínculos de parentesco-disputan criterios dispuestos por los adultos, entre ellos, como expusimos, la decisión de organizar los grupos según el avance en los aprendizajes.

En forma paralela, cuando detenemos la mirada en los espacios de uso común, no podemos pasar por alto una densidad importante de prácticas y resoluciones que tienen lugar, por ejemplo, en torno al recinto donde se prepara la comida y que tiene a las decisiones de los chicos y chicas como protagonistas. ${ }^{19}$ En las organizaciones comunitarias, al menos en su generalidad, el acceso y uso del área de la cocina atraviesa distintos momentos. Es usual que, cuando se abre una iniciativa, las cocinas cobren un gran dinamismo: por un lado, quedan conquistadas por quienes tienen a cargo la tarea de preparar las colaciones y comidas, pero a la vez, también, por parte de educadores y cuidadores de los niños, vecinos que colaboran con el lugar y, de manera sustancial, por los propios niños. Ellos circulan y permanecen de manera habitual en este sitio de los centros comunitarios. Allí suelen guardar objetos, pedir alguna ración complementaria de comida o simplemente hacer tiempo y conversar con los adultos. Muchas veces esto sucede aun cuando se haya decidido restringir como ha ocurrido en buena parte de las experiencias- la entrada a chicos y adolescentes. Si bien las cocinas -sobre todo cuando un centro se abre en el domicilio particular de un vecino- tienen sus "puertas abiertas"; progresivamente ha comenzado a ganar terreno la visión que hace hincapié en preservar a los niños -en tanto sujetos de derecho- de algunos peligros. En contradicción con esta postura, ciertos educadores instan, más bien, a la importancia de trabajar la autodeterminación y libertad de acción, no sin establecer algunas delimitaciones. Las nociones de riesgo, como develan otros estudios, apoyadas en construcciones culturales -pero principalmente sociales- sobresalen por atribuir peligrosidad a determinados elementos y al mismo tiempo niegan, olvidan u ocultan otros. Estas clasificaciones se legitiman a través de principios morales, ligadas a un sinfín de cuestiones que no son universales (pertenencia de clase, la inscripción profesional, las vivencias personales) (Grinberg, 2008). Los chicos, en el contexto de estas deliberaciones y en sus tránsitos diarios, suelen, a partir de dinámicas negociaciones, torcer algunas decisiones adultas, cuando no impugnarlas, tal como lo es la restricción al espacio "adulto" de la
18. Elsie Rockwell entiende la subversión como un proceso social, sustentado en las solidaridades, altamente formativo y no necesariamente ligado a la oposición (Rockwell, 2011).

19. En los centros comunitarios, la cocina -o el espacio que se destina para la preparación y organización de la comida- se vuelve crucial. Recordemos que en los espacios levantados por vecinos y militantes, si bien el apuntalamiento del alimento no es necesariamente la actividad exclusiva o central, éste constituye una dimensión muy significativa. No solo lo es porque los niños, atravesados por hondos procesos de desigualdad, ven muchas veces cercenado el derecho a una buena alimentación, sino porque el momento de la comida se configura como espacio muy relevante de socialización y también como experiencia formativa. 
cocina. Esto tiene lugar en función de cómo interpretan sus necesidades, siempre en controvertidas redes de relaciones condicionadas (Fraser, 1991).

Ahora, bien, en función de visibilizar el modo en que los chicos y las chicas interpretan y exponen sus necesidades, no podemos desatender procesos de autodeterminación más directa, tales como los que se ponen en juego en el procedimiento de ingreso y también de pertenencia a los espacios comunitarios. Los centros destinados a la infancia (culturales, de apoyo escolar, recreación) no se rigen, como ocurre en el sistema formal de escolarización, por la obligación de asistencia. Aun así, camadas de niños forman parte del plantel de las organizaciones sociales a lo largo de muchos años. Y si bien la entrada de un niño en uno de estos espacios queda establecida por decisión de los padres o familiares (cuando no vecinos, o instituciones que trabajan con los chicos), en diversas circunstancias son los propios chicos o adolecentes quienes se acercan a las instituciones barriales y realizan la inscripción. Distintas motivaciones conducen a que, de manera autogestiva, niños y adolescentes decidan formar parte de un centro. Los que entrevistamos en esta investigación coincidieron en que "es un espacio necesario", sobre todo en vista de ciertas vicisitudes en la vida familiar o necesidades concretas que no se solucionan en otros espacios. Así nos lo relató Gabriela, una joven que entrevistamos y que de niña había integrado el apoyo escolar en el barrio Reconquista en Tigre:

Cuando empecé a venir acá [por el centro de apoyo escolar], yo me anoté. Mi hermana mayor nada más trajo mis papeles, yo le dije que me vaya a sacar fotocopias, y bueno, de ahí agarré y me vine y me anoté. En ese momento tenía nueve años [...] Nosotros con mis hermanos faltamos un par de meses a la escuela y vino la directora a casa y mi papá le explico la situación y se preocupó porque iban a mandar a la asistente social [...]. Un día se fue mi mamá a escondidas de mi papá, ninguno de nosotros sabíamos... Después de pasados dos años supimos dónde estuvo mi mamá, bueno, y nosotros en esos dos años intentamos ir a la escuela, mis hermanos más chiquititos no iban porque mi papá no se podía encargar porque trabajaba y nosotros nos quedábamos solos en casa. [...] Yo sola me arreglaba para tener mis cosas, mis cuadernos, al final yo sola me arreglaba para cambiar de escuela. Y ahí decidí venir acá [por el apoyo escolar], venían muchos chicos y era lindo, había paseos. (Entrevista a Gabriela, exintegrante de un centro infantil, partido de Tigre, 23 de julio de 2003)

Tal como expone en su relato Gabriela, y en base a lo relevado en la investigación, es posible sostener que la imagen sobre las organizaciones comunitarias como sitios privilegiados para la infancia permeó las representaciones de los adultos, pero también la de los propios niños. En función de ese estatus otorgado, diariamente los chicos y las chicas son ávidos al momento de elevar demandas y peticiones a quienes organizan las acciones. Los niños y adolescentes se posicionan de manera activa frente a las propuestas que generan los responsables de los espacios barriales, pero nada implica que en ese proceso no realicen cuestionamientos o exijan cambios o resignificaciones en el rumbo de las acciones.

Para cerrar el análisis, en los procesos que estamos considerando, el protagonismo de los niños y adolescentes avanza hacia formas más orgánicas. En algunas experiencias comunitarias, la apertura de iniciativas y/o espacios específicos dentro de los centros tiene como actores principales a sus futuros destinatarios. En su desarrollo, las organizaciones, como expusimos, fueron variando sus propuestas de trabajo, en ocasiones suprimiendo actividades, en otras ampliándolas. Es importante decir que la alteración de estas acciones, sobre todo en lo relativo a su intensificación, muchas veces pesan las influencias concebidas en 
la órbita estatal. Subsidios y formas de financiamiento de diverso tipo traccionan el rumbo que asumen las iniciativas. Sin embargo, en varias experiencias, el surgimiento de líneas de trabajo y/o la generación de nuevos espacios están relacionados con la acción directa de quienes resultan sus beneficiarios. Esto es así particularmente para el caso de proyectos destinados a jóvenes, tal como lo expresa la siguiente nota de campo situada en uno de los barrios del noroeste, mientras en nuestro país transitábamos la crisis del año 2001. Se trata de la experiencia relatada por Daniel, un joven poblador en uno de los barrios en el noroeste del Gran Buenos Aires, que actualmente se desempeña como educador a cargo del trabajo con jóvenes en un centro comunitario:

\begin{abstract}
Y, nosotros nos empezamos a juntar a la noche en el centro. Ahí pedimos la comida ya que no comíamos al mediodía [...]. Y ahí una de las abuelas de uno de los chicos, o si no, algunas mamás venían y nos cocinaban a la noche. Sin tener ni idea ni nada, o sea, nos juntábamos a cenar y a estar nosotros en algún lugar. Eran tiempos, imaginate, 2003, 2004, 2005. [Entonces] el grupo de jóvenes empieza en el 2002, 2003, después de una crisis importante donde, por ejemplo, el barrio no estaba bueno. Acá, la zona no estaba buena para pibes como nosotros, pibes que teníamos 12, 13, 14, 15. entonces nosotros veníamos a juntarnos acá. [...] Empezamos un grupo de diez. Terminamos siendo cincuenta [...] Cincuenta jóvenes que ya teníamos un camino. Después nosotros empezamos a exigir, ponele. Le empezamos a exigir al espacio. Ya teníamos la comida, pero no era solo venir y estar sentado hasta que esté la comida, comer y después listo. No sé, después empezamos a decir "queremos talleres", o cosas, bueno, hagamos algo acá ya que estamos acá. Y ellos, bueno: “¿qué quieren hacer?”, nos dijo la coordinadora, que en ese tiempo estaba ella sola.
\end{abstract}

En el proceso de trabajo en las iniciativas comunitarias, no solo la trayectoria de los adultos se ve modificada, sino también -al decir de los mismos protagonistas- la de jóvenes y niños. Progresivamente, los chicos comienzan a integrar y formar parte de una serie de actividades con incidencia en la experiencia, entre ellas, quedar incluidos en espacios diversos de formación política, cuando no participar de acciones de demanda y reclamo en el espacio público.

\title{
Reflexión final
}

En este trabajo nos propusimos ahondar en las formas en que en nuestra contemporaneidad se gestan y producen imágenes en torno a la infancia y sus necesidades en contextos atravesados por la desigualdad social. Lo hicimos atendiendo a iniciativas impulsadas por actores de base que se han planteado una propuesta colectivizada del cuidado de los niños. La intención fue evitar un análisis que ofrezca sentidos de manera anticipada a la descripción en terreno, sustentado en visiones estáticas sobre las experiencias y los sujetos involucrados en los procesos bajo estudio.

Tal como se puso de relieve, la elaboración de ideas y acciones acerca de aquello que los niños y niñas necesitan, lejos de constituir formas ideológicas acabadas, consiste en una construcción dinámica y relacional de sentidos que, en los contextos en que investigamos, generaron voluntarios, militantes y pobladores desde posiciones y lugares novedosos que fueron ocupando. Por contrapartida a una línea de continuidad fija, en las experiencias que analizamos, las ideas en cuanto a qué significan los chicos y cuáles son sus reales necesidades implicó una específica sensibilidad -o, mejor dicho, sensibilidades- producida desde intuiciones, discernimientos y afectos, en clave de subjetividad política, y que 
fue mutando, en simultáneo mutaban, desde sus movilidades, las propias vidas de quienes encararon las acciones.

Los procesos de subjetivación política no se restringen al mundo adulto, ya que incluyen fuertemente a los niños. En paralelo con los impulsores de las obras, los niños y adolescentes, logrando posicionarse en un lugar dispuesto para la disputa, son partícipes activos de las acciones que los tienen por objeto y de la interpretación de sus necesidades. Tomando los términos que desarrolla Fraser (1991), en determinadas circunstancias, necesidades "latentes" rompen las envolturas de lo privado que las contenían y se politizan en términos contestatarios al orden dado.

Según entendemos, en tanto partícipes y hacedores de los proyectos colectivos emergentes que integran, niños y adultos crean sentidos sobre el cuidado y las necesidades desde las constricciones e imágenes que se imponen, pero también desde lugares disponibles para la acción en las dinámicas que abren aprendizajes compartidos y saberes en continua transformación. Tal como dimos cuenta en el análisis, aludimos a una construcción que contiene un componente subjetivo sustancial -aunque no por eso falto de efectos materiales concretos- y que sobresale por tener lugar en el marco de acontecimientos que cuentan con la peculiaridad de haber alterado, en todas las experiencias que conocimos, la vida cotidiana de las personas. Referimos a una alteración que incide en las formas de comprender y actuar en la realidad que se vive, en el desenvolvimiento de espacios sociales que no precisamente son pensados -al menos en un principio- para formar parte de la arena de la política y lo político.

\section{Financiamiento}

Este documento es resultado del financiamiento otorgado por el Estado Nacional, por lo tanto queda sujeto al cumplimiento de la Ley № 26.899, UBA, Programa UBACyT, 20020170100553 BA, Argentina, Ciudad de Buenos Aires, Educación y cuidado infantil en el marco de las redefiniciones sobre lo público y lo privado: imbricaciones y dinámicas estatales, domésticas y colectivas analizadas desde un enfoque etnográfico y Proyecto PICT Experiencias formativas y responsabilidades respecto a la educación y el cuidado infantil. Obligaciones y prácticas sociales de y en torno a los niños y las niñas en las redefiniciones sobre lo público y lo privado, FONCyT. Agencia Nacional de Promoción Científica y Tecnológica.

\section{Agradecimientos}

Agradecemos al Concejo Nacional de Investigaciones Científicas y Técnicas (CONICET), a la Universidad de Buenos Aires y a la Agencia Nacional de Promoción Científica y Técnica que han hecho posible esta investigación, así como a todas las personas entrevistadas, quienes son parte sustantiva de la experiencia que describimos en este artículo.

\section{Sobre la autora}

Laura Santillán es Doctora por la Universidad de Buenos Aires, Área Antropología. Investigadora Independiente en el CONICET, Argentina, y directora del equipo de investigación "Educación y cuidado infantil en el marco de las redefiniciones sobre lo público y lo privado: imbricaciones y dinámicas estatales, domésticas y colectivas analizadas desde un enfoque etnográfico" (UBA). Profesora Adjunta del Departamento de Ciencias Antropológicas (FFyL, UBA) y Universidad Nacional de José C. Paz. 


\section{Q Referencias bibliográficas}

》 Achilli, E. (2005). Investigar en Antropología Social. Los desafíos de transmitir un oficio. Rosario: Laborde Editor.

" Alvarado, S. V., Botero, P. y Ospina, H. F. (2010). Subjetividades políticas: sus emergencias, tramas y opacidades en el marco de la acción política. Mapeo de 61 experiencias con vinculación de jóvenes en Colombia. Utopía y Praxis Latinoamericana, 15(50), 39-55.

"Barna, A. (2012). Convención Internacional de los Derechos del Niño. Hacia un abordaje desacralizador. Kairós. Revista de Temas Sociales, 16(29), 2-19.

» Batallán, G. (2011). La invisibilidad de los niños y jóvenes en el debate sobre la participación política. Puntos críticos desde una perspectiva histórico-etnográfica de investigación. En G. Batallán y M. R. Neufeld (Eds.), Discusiones sobre infancia y adolescencia. Niños y jóvenes, dentro y fuera de la escuela (pp. 15-24). Buenos Aires: Biblos.

» Bourdieu, P. (2000). Cuestiones de sociología. Madrid: Istmo.

" Cardarelli, G. (2005). Los niños están en todas partes. Modalidades "formales” y “no formales" de atención a la primera infancia. En M. Pereira (Ed.), Intervenciones en primera infancia (pp. 23-44). Buenos Aires: Novedades educativas.

"Carli, S. (2002). Niñez, pedagogía y política. Transformaciones de los discursos acerca de la infancia en la historia de la educación argentina entre 1880 y 1955. Buenos Aires: Miño y Dávila.

"Cerletti, L. (2014). Familias y escuelas. Tramas de una relación compleja. Buenos Aires: Biblos.

"Chatterjee, P. (2011). La política de los gobernados. Revista Colombiana de Antropología, $47(2), 199-231$.

»Cohn, C. (2005). Antropologia da Criança. Río de Janeiro: Jorge Zahar.

"Colángelo, A. (2005). La mirada antropológica sobre la infancia. Reflexiones y perspectivas de abordaje. Serie Encuentros y Seminarios. Recuperado de www.me.gov.ar/curriform/ publica/oei_20031128/ponencia_colangelo.pdf

"Cura, F. (2013): Organizaciones sociales, Estado y políticas: un estudio etnográfico sobre el proceso de conformación de un Bachillerato Popular en la zona norte del Área Metropolitana de Buenos Aires. Revista de Sociología y Antropología Virajes (14), 95-116.

»De Certeau, M. (1996). La invención de lo cotidiano I. Artes de hacer. México: Universidad Iberoamericana.

"Enriz, N. (2010). Juegos, saberes y experiencias infantiles mbyá-guaraní en Misiones (Tesis de Doctorado). Facultad de Filosofía y Letras, Universidad de Buenos Aires, Buenos Aires, Argentina.

» Fonseca, C. (1998). Caminos de adopción. Buenos Aires: Eudeba.

»Fraser, N. (1991). La lucha por las necesidades: esbozo de una teoría crítica socialista feminista de la cultura política del capitalismo tardío. Revista Debate Feminista, 3, 3-40.

" García Palacios, M. y Hecht, C. (2009). Los niños como interlocutores en la investigación antropológica. Consideraciones a partir de un taller de memorias con niños y niñas indígenas. Revista Tellus, 17(9), 163-186. 
»Gentile, M. F. (2011). Niños, ciudadanos y compañeritos: un recorrido por los distintos criterios para el trabajo de inclusión social de niños y adolescentes de sectores vulnerables. En I. Cosse, V. Llobet, C. Villalta y C. Zapiola (Comps.), Infancias: políticas y saberes en Argentina y Brasil (siglos XIX y XX) (pp. 265-286). Buenos Aires: Teseo.

» González, F. (2012). La subjetividad y su significación para el estudio de los procesos políticos: sujeto, sociedad y política. En C. Piedrahíta, A. Díaz y P. Vommaro (Comps.), Subjetividades políticas: desafíos y debates latinoamericanos (pp. 11-30). Bogotá: Universidad Distrital Francisco José de Caldas.

» Grinberg, J. (2008). Transformaciones en el tratamiento de la niñez en riesgo. Reflexiones sobre un dispositivo de protección a la infancia en la Ciudad de Buenos Aires. Cuadernos de Antropología Social, 27, 155-174.

» Grossberg, L. (1992). Power and Daily Life. En We gotta get out of this place. popular conservatism and postmodern culture (pp. 89-111). Nueva York: Routledge.

» Grossberg, L. (2012). Estudios culturales en tiempo futuro. Buenos Aires: Siglo XXI.

» Hardman, C. (1973). Can there be an Anthropology of children? Journal of the Anthropological Society of Oxford, 4 (2). 85-99.

»Ingold, T. (2015). Contra el espacio: lugar, movimiento, conocimiento, Mundos Plurales, 2(2), 9-26.

»Llobet, V. (2010). ¿Fábricas de niños? Las instituciones en la era de los derechos de la infancia. Buenos Aires: Noveduc.

» Manzano, V (2013). La política en movimiento. Movilizaciones colectivas y políticas estatales en la vida del Gran Buenos Aires. Rosario: Protohistoria.

» Massey, D. (2012). Espacio, lugar y política en la coyuntura actual. Urban NSo4, 7-12.

" Moreno, J. (2000). La política social antes de la política social. Buenos Aires: Prometeo.

»Padawer, A. (2003). A la buena de Dios: las escuelas y la frontera entre las edades en un contexto de exclusión. Ponencia presentada en Reunión de Antropología del Mercosur. Florianópolis, Brasil.

» Pires, F. (2007). Ser adulta e pesquisar crianças: explorando possibilidades metodológicas na pesquisa antropológica. Revista de Antropología, 50(1), 225-270.

» Rockwell, E. (2009). La experiencia etnográfica. Historia y cultura en los procesos educativos. Buenos Aires: Paidós.

» Rockwell, E. (2011). Los niños en los intersticios de la cotidianeidad escolar. ¿Resistencia, apropiación o subversión? En G. Batallán y M. R. Neufeld (Eds.), Discusiones sobre infancia y adolescencia. Niños y jóvenes, dentro y fuera de la escuela (pp. 15-24). Buenos Aires: Biblos.

» Roseberry, W. (2007): Hegemonía y el lenguaje de la controversia. En M. Lagos y P. Calla (Comps.), Antropología del Estado. Dominación y prácticas de contestatarias en América Latina (PP. 17-137). La Paz: PNDU.

»Rosemberg, F. (1999). Expansao da educacao infantil e procesos de exclusao. Cadernos de Pesquisa, 17, 7-40.

» Santillán, L. (2012). Quiénes educan a los chicos. Infancia, trayectorias educativas y desigualdad. Buenos Aires: Biblos.

» Santillán, L. (2014). El cuidado y la educación infantil en experiencias comunitarias: un análisis antropológico sobre las prácticas locales y la acción colectiva en barrios populares de Buenos Aires. Revista Educacao, Sociedad \& Culturas (46). 91-108. 
"Santillán, L. (2015). La demanda por educación en barrios populares del Gran Buenos Aires: acerca de la militancia política, el voluntariado social y la actuación colectiva de los pobladores (1985 y 2015). Actas de la XI Reunión de Antropología del Mercosur. Montevideo, Uruguay.

»Santillán, L. y Novaro, G. (2017). Organizaciones populares, niñez y educación: un estudio en centros sociales barriales y asociaciones de migrantes. En G. Novaro, L. Santillán, A. Padawer y L. Cerletti (Comps.), Niñez, regulación estatal y procesos de identificación. Experiencias formativas en contextos de diversidad y desigualdad (pp. 15-43). Buenos Aires: Biblos.

"Scheper-Hughes, N. (1999). La muerte sin Ilanto. Violencia y vida cotidiana en Brasil. Barcelona: Ariel.

$»$

»Shabel, P. (2016). "Venimos a jugar y a luchar”. Participación política de niños y niñas en organizaciones sociales. Lúdicamente, 10(5), 1-14.

"Szulc, A. (2006). Antropología y niñez: de la omisión a las “culturas infantiles”. En G. Wilde y P. Schamber (Eds.), Cultura, comunidades y procesos contemporáneos (pp 25-51). Buenos Aires: SB.

"Vargas, V., López, L. y Guevara, N. (2009). Constitución de sujeto político: historias de vida política de mujeres líderes afrocolombianas. Universitas Psychologica, 8(3), 639-652.

»Villalta, C. (2010). Infancia, justicia y derechos humanos. Bernal: Universidad Nacional de Quilmes.

»Villalta, C. (2012). Entregas y secuestros. El rol del Estado en la apropiación de niños. Buenos Aires: Ediciones del Puerto/Centro de Estudios Legales y Sociales.

"Woods, M (2007). Modalidades y límites de la intervención de la Iglesia Católica en conflictos sociales territoriales. De la mediación a la confrontación en la diócesis de Quilmes. En Cravino, C (ed.) Resistiendo en los barrios. Acción colectiva y movimientos sociales en el Área Metropolitana de Buenos Aires (pp 77-99). Los Polvorines: Universidad Nacional de General Sarmiento. 
